OPEN ACCESS

Edited by:

Toby Mündel,

Massey University, New Zealand

Reviewed by:

Yi-Hung Liao,

National Taipei University of Nursing and Health Sciences, Taiwan

Damir Zubac,

University of Split, Croatia and Scientific Research Center Koper,

Slovenia

${ }^{*}$ Correspondence:

Oliver R. Barley

o.barley@ecu.edu.au

Specialty section:

This article was submitted to

Exercise Physiology,

a section of the journal

Frontiers in Physiology

Received: 07 November 2018

Accepted: 18 February 2019

Published: 05 March 2019

Citation:

Barley OR, Chapman DW Guppy SN and Abbiss CR (2019)

Considerations When Assessing

Endurance in Combat Sport Athletes.

Front. Physiol. 10:205.

doi: 10.3389/fphys.2019.00205

\section{Considerations When Assessing Endurance in Combat Sport Athletes}

\author{
Oliver R. Barley ${ }^{1 *}$, Dale W. Chapman ${ }^{1,2}$, Stuart N. Guppy ${ }^{1}$ and Chris R. Abbiss ${ }^{1}$ \\ ${ }^{1}$ Centre for Exercise and Sports Science Research, School of Medical and Health Sciences, Edith Cowan University, \\ Joondalup, WA, Australia, ${ }^{2}$ Performance Support, New South Wales Institute of Sport, Sydney, NSW, Australia
}

Combat sports encompass a range of sports, each involving physical combat between participants. Such sports are unique, with competitive success influenced by a diverse range of physical characteristics. Effectively identifying and evaluating each characteristic is essential for athletes and support staff alike. Previous research investigating the relationship between combat sports performance and measures of strength and power is robust. However, research investigating the relationship between combat sports performance and assessments of endurance is less conclusive. As a physical characteristic, endurance is complex and influenced by multiple factors including mechanical efficiency, maximal aerobic capacity, metabolic thresholds, and anaerobic capacities. To assess endurance of combat sports athletes, previous research has employed methods ranging from incremental exercise tests to circuits involving sports-specific techniques. These tests range in their ability to discern various physiological attributes or performance characteristics, with varying levels of accuracy and ecological validity. In fact, it is unclear how various physiological attributes influence combat sport endurance performance. Further, the sensitivity of sports specific skills in performance based tests is also unclear. When developing or utilizing tests to better understand an athletes' combat sports-specific endurance characteristic, it is important to consider what information the test will and will not provide. Additionally, it is important to determine which combination of performance and physiological assessments will provide the most comprehensive picture. Strengthening the understanding of assessing combat sport-specific endurance as a physiological process and as a performance metric will improve the quality of future research and help support staff effectively monitor their athlete's characteristics.

Keywords: physiological assessment, performance monitoring, measurement precision, biology of combat sports, sports specificity, aerobic capacity

\section{INTRODUCTION}

Combat sport is a term used to describe a wide range of competitive contact sports typically involving physical combat where the winner is determined by specific criteria depending on the rules of the sport. Combat sports have a large public following with sports such as boxing and mixed martial arts (MMA) having millions of followers and approximately $20 \%$ of summer Olympic 
medals available in combat sports such as boxing, judo and taekwondo (Franchini et al., 2012; James et al., 2016b; Reale et al., 2016). Combat sports can be categorized as grappling, striking or mixed style sports. Grappling sports involving gripping, throwing, ground combat, chokeholds and joint locks (Ratamess, 2011), while striking sports incorporate skills ranging from only punches to combinations of punches, kicks, knees, and elbows (Rodrigues Silva et al., 2011). Mixed style combat sports involve both grappling and striking, thus requiring a diverse skill-set (Tack, 2013). The rules vary between combat sports resulting in different methods of victory and competition durations, which in turn results in many possible competitive styles, even within the same sport (Tack, 2013). In several combat sports, specific techniques or positions are worth a set number of points and successfully applied techniques are then subsequently totalled to determine victory should an opponent not be defeated via a submission, knock-out (KO) or technical knock-out (TKO; Balmer et al., 2005; Ratamess, 2011). In contrast, some sports utilize an ever-evolving and more subjective scoring system for bouts that are not ended by a submission, KO or TKO. For example, the current scoring system applied to both amateur and professional bouts in several combat sports is referred to as the "10-Point Must System," whereby judges subjectively decide the winner of the round awarding 10 points and the opponent 9 or less. These scoring systems result in diverse methods of victory in combat sports, and thus the term "performance" is complicated. Indeed, overcoming an opponent through submission in the first minute of an event or on points after fifteen minutes of fighting would both be examples of successful competitive performances but achieved through very different physical characteristics, skill sets and tactics. Thus, for coaches and physical conditioning support personnel assessing such physical characteristics is important for optimizing athlete development, competition tactics and preparations for competition. As a result, a large body of literature has been developed around understanding the physical and physiological characteristics of combat sport athletes (Chaabene et al., 2018; James et al., 2016b).

Combat sports are physically demanding, requiring a diverse physical and physiological profile to be successful in competition (Kraemer et al., 2001; Ratamess, 2011; Bridge et al., 2014; Franchini et al., 2014; Chaabène et al., 2015). Striking movements such as punches and kicks require explosive strength and power (Loturco et al., 2014; House and Cowan, 2015), while grappling movements can require a greater emphasis on isometric and concentric strength (Ratamess, 2011; James et al., 2016b). Additionally, combat sports are comprised of many different sports-specific movements which will influence the physical load. For instance, sports such as boxing and judo exert a greater demand on the upper limbs whilst taekwondo exerts a greater demand on the lower limbs (Bridge et al., 2014; Franchini et al., 2014; Chaabène et al., 2015). Even differences in equipment requirements may influence the physical demands of the sport, such as the use of a kimono in Brazilian Jiu-Jitsu and judo increasing the use of the forearm muscles (Andreato and Branco, 2016). The specific skills and rulesets of a combat sport will significantly influence the energy cost of competition (Crisafulli et al., 2009; Andreato and Branco, 2016; Hausen et al., 2017).
However, combat sports do not typically involve a single execution of one particular technique but instead involve repeated executions interspersed with lower intensity actions (Rodrigues Silva et al., 2011; Franchini et al., 2013; Andreato et al., 2015; Miarka et al., 2015a,b). The high-intensity repeateffort nature of combat sports typically results in a large aerobic response during exercise as demonstrated by athletes reaching near maximal heart rates and oxygen consumption (>90\% of maximum $\mathrm{HR}$ and $\mathrm{VO}_{2 \max }$ ) during simulated competition (Crisafulli et al., 2009; Doria et al., 2009; Campos et al., 2012). Additionally, the high-intensity component of combat sport competitions induces significant anaerobic strain with research observing high levels of blood lactate $\left(>12 \mathrm{mmol} . \mathrm{L}^{-1}\right)$ following competition (Bouhlel et al., 2006; Hanon et al., 2015). This makes endurance an important characteristic of success in competitive combat sports (Amtmann and Berry, 2003; La Bounty et al., 2011; Ratamess, 2011; Lenetsky and Harris, 2012). However, endurance is a difficult concept to define as it is influenced by a wide range of physiological, psychological and biomechanical factors (Abbiss and Laursen, 2005). For the purposes of this review endurance will defined as the ability to maintain a highintensity or repeated efforts over longer exercise durations. The work:rest ratios of high-intensity efforts during competition vary, thus resulting in different endurance profiles between combat sports (Del Vecchio et al., 2011; Rodrigues Silva et al., 2011; Andreato et al., 2015). It is also important to consider the total duration of events in combat sports, with some sports having a single round lasting $10 \mathrm{~min}$ and others involving up to twelve $3 \mathrm{~min}$ rounds. Furthermore, it is possible that different regulations in performance enhancing drugs and weight cutting practices may also influence performance in different combat sports and levels of competition. These differences create complications when attempting to compare results acquired from exercise testing of athletes from different types of combat sports, especially Olympic and professional ones (Andreato and Branco, 2016). Additionally, the rules of many combat sports are somewhat unique and allow for an athlete to win before the allotted competition time, which makes the total duration highly variable. Indeed, it has been reported that over half of all MMA fights in the Ultimate Fighting Championship ${ }^{\circledR}\left(\mathrm{UFC}^{\circledR}\right)$ are ended within the first round (Del Vecchio and Franchini, 2013). However, it is not uncommon for fights to last the entire allocated duration (Miarka et al., 2015b). These diverse requirements, due to both the physical requirements and varied length of competition, result in athletes requiring several well-developed physical characteristics including strength, power, agility and endurance on top of technical skill and tactics to be successful (Amtmann and Berry, 2003; La Bounty et al., 2011; Ratamess, 2011). While there are a wide range of potential tools for support staff to use to assess an athlete's relevant physical characteristics, what approaches are most relevant to combat sports success currently are not clear, especially in the case of combat sports endurance related performance (Chaabene et al., 2018). As such, the purpose of this review is to provide a critical appraisal of the current methods of assessing physical capacities in combat sports with a focus on endurance ability in an effort to help develop best practice guidelines. 


\section{CURRENT PRACTICES IN ASSESSING PHYSICAL CHARACTERISTICS IN COMBAT SPORTS}

It may not be possible to develop a single test that simultaneously assesses all factors of all combat sports performance under controlled conditions. As a result, the best available approach is to assess individually characteristics integral to competitive success, such as strength, power, agility and endurance (La Bounty et al., 2011; Ratamess, 2011; James et al., 2016b) with some insight into the underlying physiology to lesser or greater degree. Effectively identifying and evaluating such characteristics is essential to inform training interventions, nutritional demands, talent identification, and design the optimal competition strategies for athletes. When selecting a test to assess a characteristic in combat sports athletes, it is important to differentiate between tests where the primary outcome measure is an indicator of physiological capacity or performance. Tests of performance are primarily used to simulate competition in a controlled manner as opposed to assessing the function of a physiological system (Bassett and Howley, 2000; Currell and Jeukendrup, 2008). When evaluating the body of research investigating key physical characteristics in combat sports, it is apparent that the employed methods range from physiological assessments with low sports specificity to performance assessments with high sports specificity (Franchini et al., 2011; Chaabène et al., 2012; James et al., 2016b). Thus assessments seeking to isolate an underlying physical characteristic with low sports specificity used across combat sports include: one repetition maximum (1RM) testing (Franchini et al., 2007; Garthe et al., 2011; James et al., 2016b), maximal isokinetic strength assessment (Timpmann et al., 2008), counter-movement and squat jumps (Fogelholm et al., 1993; Garthe et al., 2011; Ouergui et al., 2014; James et al., 2016b; Barley et al., 2018b), 40-m sprint (Garthe et al., 2011), 30 s continuous jump (Čular et al., 2018), repeated contractions on an isokinetic dynamometer (Moore et al., 1992; Kraemer et al., 2001; Oopik et al., 2002; Timpmann et al., 2008; Barley et al., 2018a), Wingate testing (Fogelholm et al., 1993; Artioli et al., 2010; Mendes et al., 2013; Durkalec-Michalski et al., 2014; Ouergui et al., 2014), various repeat-sprint tests (Barley et al., 2018b; James et al., 2018) and maximal aerobic capacity testing (Guidetti et al., 2002; Ravier et al., 2006; Franchini et al., 2011; Bruzas et al., 2014; Reljic et al., 2015; James et al., 2016b). As the spectrum of physical assessments shifts toward a higher level of sport specificity assessment, examples include exercise circuits (i.e., burpees, press-ups, and sports-specific skills such as throws or strikes) (Smith et al., 2000; Franchini et al., 2005, 2007, 2011; Hall and Lane, 2001; Artioli et al., 2010; Chaabène et al., 2012; Villar et al., 2016; Sant'Ana et al., 2017) and simulated combat with a live opponent (Yang et al., 2018) (Table 1). Although the use of such testing modalities appears sound, critical evaluation of the ecological validity of the test or physiological characteristic involved is required, including an understanding of the precision to detect small but important changes.

There is a belief that when assessing a performance characteristic, the assessment should relate as closely as possible to the sport itself. However, there can be a trade-off between precision of measurement for the physical characteristic and maintaining sporting relevance. While some assessment methods of physical characteristics closely relate to competitive success (James et al., 2016a,b), the relationship for others is much less clear (James et al., 2016b). For example, greater levels of strength and power have been linked to a higher competitive level in combat sports (James et al., 2016a,b) and to greater punching force (Loturco et al., 2014; House and Cowan, 2015). In fact, it appears that the body of research assessing strength and power in combat sports athletes is robust (Loturco et al., 2014; House and Cowan, 2015; Iermakov et al., 2016; James et al., 2016a,b). In contrast, the methods of assessing combat sports-specific endurance are highly varied in the literature and much less robust (Chaabene et al., 2018). This is likely due to the complex nature of endurance as a physical characteristic underpinning combat sport performance, making it far more complicated to assess. Indeed, it is acknowledged that the demand on the aerobic system varies depending on intensity and competition length, with sports involving multiple rounds such as boxing, kickboxing and MMA placing a greater strain on the aerobic system (Smith, 1998; La Bounty et al., 2011; Rodrigues Silva et al., 2011; Alm and Yu, 2013; Del Vecchio and Franchini, 2013; Chaabène et al., 2015). Additionally, sports with single rounds likely require a significant aerobic contribution (Chaabène et al., 2012; Ratamess, 2011; Franchini et al., 2014). However, it is important to note that endurance is influenced by many more factors than just aerobic capacity (Coyle, 1999; Bassett and Howley, 2000; Aziz et al., 2007; Buchheit, 2008; Aguiar et al., 2016). The repeated high-intensity efforts involved require competitive athletes to have well developed strength-endurance, efficiency and anaerobic capacities alongside a capacity to rapidly recover (Coyle, 1999; Ratamess, 2011; Bridge et al., 2014; Chaabène et al., 2015; Salci, 2015). Thus, to better understand endurance ability in a combat sport athlete it is important to consider all factors relevant to the individual combat sport's-specific endurance. Given the lack of clarity in the literature regarding the assessment of endurance relevant to combat sports, the following sections seek to provide recommendations for methods of evaluating characteristics relevant to endurance ability in combat sports athletes.

\section{ASSESSING ENDURANCE IN COMBAT SPORTS ATHLETES FROM A PERFORMANCE PERSPECTIVE}

When assessing endurance performance, the overall duration and intermittent nature of the specific combat sport should be taken into account (Del Vecchio and Franchini, 2013). Combat sports with multiple rounds can involve greater than $30 \mathrm{~min}$ of highintensity intermittent activity (Guidetti et al., 2002; Andreato and Branco, 2016). Additionally, combat sport bouts involve the use of a wide range of sports-specific skills that can also influence the physical requirements which may be difficult to replicate under controlled conditions (Bridge et al., 2014; Franchini et al., 2014; Chaabène et al., 2015; Andreato and Branco, 2016). Whilst it 


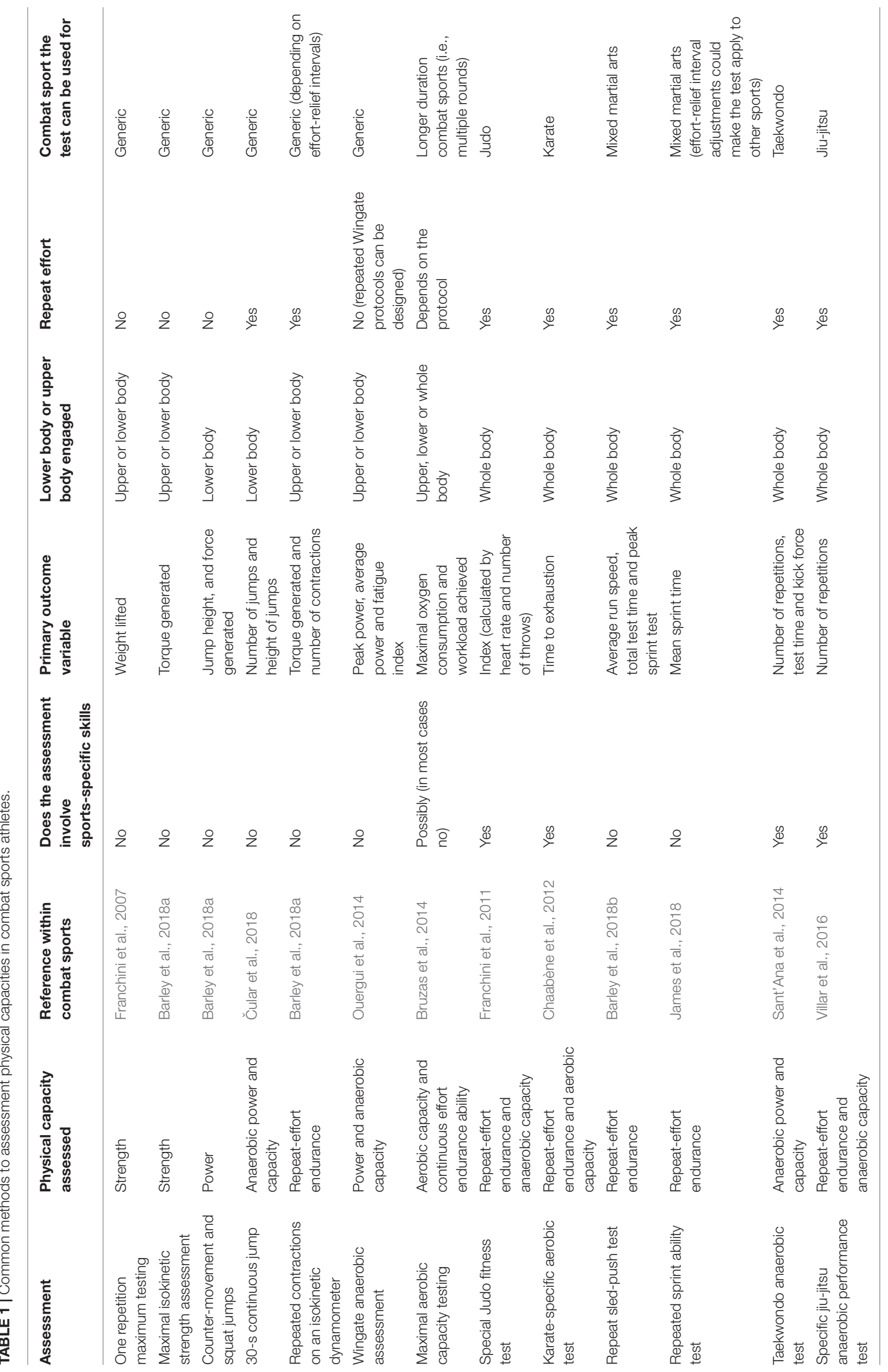


is generally understood that utilizing sports-specific assessments is ideal (Müller et al., 2000), developing a sports-specific and scientifically valid assessment of endurance for all combat sport athletes is difficult. This is due to the high degree of variation in the physiological demands, sports-specific skills and competitive approaches both between and within combat sports (Franchini et al., 2011; Chaabène et al., 2012).

The variation between and within combat sports complicates the assessment of endurance in such athletes. As a result, researchers examining endurance capacity in combat sport athletes have utilized a range of assessment methods. These include circuits of activities conducted in a manner that reflect the required physical and physiological load of the specific sport, and in many cases, including sports-specific skills such as strikes and throws to mimic the performance aspects required (Smith et al., 2000; Hall and Lane, 2001; Franchini et al., 2005, 2007, 2011; Artioli et al., 2010; Chaabène et al., 2012; Villar et al., 2016; Sant'Ana et al., 2017) (Table 1). In locomotion sports such as cycling or running, the goal of any assessment is to evaluate such locomotion as this is the context in which competitive performance occurs. But in sports such as combat sports, where locomotion is not the sole objective, there are many goals and measures of possible performance. Specifically, the ability to continually attack and defend effectively against an opponent during later rounds is essential to victory (Miarka et al., 2015b). The ability to continue to execute sports-specific skills over longer periods of time despite fatigue has been assessed in judo (Franchini et al., 2011), karate (Chaabène et al., 2012), boxing (Smith et al., 2000), taekwondo (Sant'Ana et al., 2014) and Brazilian jiu-jitsu (Villar et al., 2016) (Table 1). These tests all involve the repeated execution of one or more sports-specific skill for an allocated time or until volitional fatigue, with varying measurements recorded. Simulation-style tests such as these provide valuable information on the fatigue induced by such sports-specific drills. There remain however many combat sports that do not have sports-specific performance tests available, and future research should aim to address this gap in available methodology. While it is important to consider that the potential limitations of such testing methods have not been completely explored, these include aspects related to the precision of in situ aerobic capacity measurement, lactate and ventilatory threshold identification and more general instances of measurement and repeatability of test performance. The special judo fitness test has undergone reliability testing as well as physiological examination (Franchini et al., 2009, 2011). Indeed, ventilatory gas analysis identified that $28.2 \pm 2.9 \%$ of energy requirement were aerobic during this test (Franchini et al., 2011). An issue with this and many other performance based tests is that they are unable to assess important physiological characteristics such as thresholds, efficiency of motion or others likely to be relevant to performance. Regardless, typical tests of repeatability are derived from locomotion tasks, such as repeated-sprint ability, where the relationship between fatigue and changes in biomechanics is better understood (Morin et al., 2006). However, in combat sports the changes in technical ability resulting from fatigue and how important such changes are to competitive success are not clear. Given the highly technical nature of combat sports it is plausible that fatigue-induced reductions in skill would have an even greater impact on competitive success than in locomotion based sports. Current sports-specific protocols do not comprehensively monitor impairments in skill which could result in missing important information that would plausibly have a substantial influence on performance during real competition. To better understand this future research should investigate the specific kinematic changes in combat sports techniques resulting from fatigue.

Repeat-effort ability is regarded as essential in a wide range of sports outside of those centered on combat. As a result there is a substantial body of literature that examines the repeat-effort ability of athletes (Bishop et al., 2001). While assessments of repeat-effort ability will have a similar basic structure, they can vary in a range of ways, including the duration of efforts, the recovery duration and number provided, and the modality of exercise (Bishop et al., 2001; Aziz et al., 2007). Previously reported testing protocols have involved repeated sprints on foot (Zagatto et al., 2009; James et al., 2018), on a cycle ergometer (Bishop et al., 2001), upper-body ergometer (Mendes et al., 2013), or pushing a sled (Barley et al., 2018b). Generic running tests such as the 30-15 intermittent fitness test are common examples of repeat-effort running tests commonly used in the field (Aziz et al., 2000; Buchheit, 2008; James et al., 2018), although the work-rest ratios are unlikely to be reflective of combat sports competitions. Many repeat-effort assessments however, only measure the highintensity component (i.e., the sprint duration) while neglecting the low-intensity recovery portion, which potentially results in missing important information (Balsom et al., 1992; Spencer et al., 2005; Barley et al., 2018b; James et al., 2018). For example, when assessing repeated sprints on a cycle ergometer it is common for the tester to require the athlete to maintain at least $60 \mathrm{rpm}$ during the recovery period. Yet it is very often unreported whether this protocol factor was adhered to and thus, although seeking to standardize recovery, the potential insight for the efficacy of an athlete's recovery process is lost.

Combat sports athletes require the ability for continual movement about the competitive arena for positioning an opponent and an ability for sustained upper-body isometric and dynamic contractions. While some of the repeat-effort data collected using common methods could elucidate this performance aspect, it is important to consider that sustained upper body isometric and dynamic contractions are not reflected easily in most repeat-effort testing as the methods used do not require significant strength, and therefore would not likely translate to combat sports. Previous research has tried to mitigate this issue with varying degrees of ecological validity by requiring athletes (judokas) to perform a series of unopposed throws of an opponent in their weight category between brief sprints (Franchini et al., 2011) or, alternatively, to push a weight sled (body mass relative) maximally for a specific distance (Barley et al., 2018b). However, these methods require further investigation to determine their applicability to their respective sports considering the aforementioned limitations of such protocols. Additionally, it is also important to consider if factors such as the level of competition or biological sex will influence the best practices for assessing physical 
capacities in combat athletes, which should be a topic of future research.

\section{ASSESSING ENDURANCE IN COMBAT SPORTS ATHLETES FROM A PHYSIOLOGICAL PERSPECTIVE}

Repeat-effort ability is maintained by a complicated relationship between anaerobic and aerobic metabolism, with the anaerobic system being mostly important in high-intensity performance and the aerobic system being important to recovery between efforts (Bishop et al., 2011; Girard et al., 2011). The initial highintensity effort will be heavily reliant on anaerobic metabolism with increasing aerobic contribution as more efforts are completed (Girard et al., 2011). However, even in the final efforts of repeat-sprint protocols the majority of energy can still be yielded anaerobically, though to a lesser extent (Girard et al., 2011). A study by McGawley and Bishop (McGawley and Bishop, 2015) observed significant aerobic contribution in the final sprint of a $5 \times 6$-s maximal sprint protocol. As such, the high-intensity components of repeat-effort sports will be significantly influenced by an athlete's anaerobic capacity even as the competition duration extends (Girard et al., 2011). Indeed, repeat-effort performance is likely to be heavily influenced by the accumulation of metabolic by-products, limitations in energy supply and neural fatigue (Girard et al., 2011). This is supported by studies that observe significant increases in blood metabolites during combat sports competitions (Bouhlel et al., 2006; Hanon et al., 2015) and the maximal cardiac response associated with combat sports competitions (Crisafulli et al., 2009; Hausen et al., 2017). As a result, common assessments of anaerobic capacity such as a Wingate or maximal accumulated oxygen deficit (MAOD) assessment will likely have important implications to combat sports endurance ability (Vandewalle et al., 1987; Faude et al., 2009; Bishop et al., 2011). The relationship between anaerobic capacity and competitive level in combat sports athletes has been observed in previous research (James et al., 2016b). However, the ability to recover from such high-intensity efforts during the low-intensity components will be driven primarily by the aerobic system to buffer hydrogen ion concentration and enhance phosphocreatine (PCr) regeneration (Balsom et al., 1992; Girard et al., 2011). This has been confirmed by previous research investigating the energy demands in taekwondo athletes during combat simulation (Campos et al., 2012). As such, greater aerobic fitness will likely improve repeat-effort ability in combat sports competitions by increasing oxygen availability, improving lactate removal and enhancing PCr regeneration (Tomlin and Wenger, 2001; Bishop et al., 2011). Increased aerobic fitness will also induce many physiological adaptations which could aid in combat sports endurance such as increased mitochondrial respiratory capacity, faster oxygen uptake kinetics, accelerated post-effort muscle reoxygenation rate, improved lactate and ventilatory thresholds and a greater $\mathrm{VO}_{2 \max }$ (Bishop et al., 2011). However, it is important to remember that the relationship between maximal aerobic capacity and combat sports competitive level, or even repeat-effort performance in general does not appear to be linear (Bishop et al., 2011; Girard et al., 2011; Bridge et al., 2014; James et al., 2016b). We postulate that at the higher levels of combat sport competition there is a diminishing rate of return in the gross markers of aerobic capacity and adaptation. In fact, previous research has found sports-specific aerobic training in judo athletes to not improve $\mathrm{VO}_{2 \max }$ but to significantly affect ventilation thresholds, heart rate and $\mathrm{VO}_{2}$ recovery (Bonato et al., 2015). As such, other markers of aerobic fitness such as metabolic thresholds, economy, oxygen kinetics and the power output associated with $\mathrm{VO}_{2 \max }$ could more closely relate with fatigue development during repeat-effort exercise as observed in combat sports (Faude et al., 2009; Bishop et al., 2011). Due to the aforementioned differences between intermittent and continuous exercise, the ecological validity would increase if practitioners were to evaluate such factors during intermittent exercise protocols (Drust et al., 2000; Koralsztein and Billat, 2000) particularly with world class athletes. Further research is required to better understand exactly which markers of both anaerobic and aerobic fitness best relate to combat sports endurance.

\section{CONCLUSION}

Combat sports are popular, physically demanding sports with a diverse competitive cohort around the globe. With a developing body of research, it is important to critically examine the current practices and how these may be best applied by the practitioner in the monitoring of athlete adaption process. Such a body evidence will not only help inform the assessment of endurance in combat sports athletes, but also the development of physical capacities which is a topic that needs further investigation. The current assessments of characteristics important for competitive combat sports performance, particularly those involved with endurance require further evaluation to determine their efficacy. This is important as many of the current methods may not be accurately assessing endurance ability or may lack the sensitivity to detect any changes. Endurance is a complicated characteristic comprised of many factors and as such cannot be comprehensively evaluated with a single test. A combination of assessments designed to simulate aspects of performance (in particular, repeat-effort ability) and others designed to better understand the underlying physiology will provide the most complete picture of combat sport endurance ability. However, while there is research investigating what physiological markers are important for combat sport athletes further research is needed to understand the relevant importance of variables such as metabolic thresholds and oxygen kinematics. When designing a test to simulate combat sport-specific endurance there are many things to consider, including how to induce a comparable physical and physiological load to competition alongside carefully choosing what activities will be included in the testing with respect to their ecological and scientific validity. Future research should investigate the potential impact that fatigue may have on combat sports-specific techniques and how such changes may influence assessments of endurance. Developing a better understanding the issues presented throughout this 
review will improve researchers' ability to accurately assess characteristics relevant to combat sports performance, alongside allowing coaching staff to make appropriate training decisions and more effectively monitor the impact of such decisions.

\section{REFERENCES}

Abbiss, C. R., and Laursen, P. B. (2005). Models to explain fatigue during prolonged endurance cycling. Sports Med. 35, 865-898. doi: 10.2165/00007256200535100-00004

Aguiar, R. A. D., Raimundo, J. A. G., Lisbôa, F. D., Salvador, A. F., Pereira, K. L., Cruz, R. S. D. O., et al. (2016). Influence of aerobic and anaerobic variables on repeated sprint tests. Rev. Bras. Educ. Fís. Esporte 30, 553-563. doi: 10.1139/ apnm-2014-0431

Alm, P., and Yu, J. (2013). Physiological characters in mixed martial arts. Am. J. Sports Sci. 1, 12-17. doi: 10.11648/j.ajss.20130102.11

Amtmann, J., and Berry, S. (2003). Strength and conditioning for reality fighting. Strength Cond. J. 25, 67-72. doi: 10.1519/00126548-200304000-00012

Andreato, L. V., and Branco, B. H. M. (2016). Different sports, but the same physical and physiological profiles? Sports Med. 46, 1963-1965. doi: 10.1007/ s40279-016-0587-9

Andreato, L. V., Julio, U. F., Panissa, V. L. G., Esteves, J. V. D. C., Hardt, F., de Moraes, S. M. F., et al. (2015). Brazilian jiu-jitsu simulated competition Part II: physical performance, time-motion, technical-tactical analyses, and perceptual responses. J. Strength Cond. Res. 29, 2015-2025. doi: 10.1519/JSC. 0000000000000819

Artioli, G. G., Iglesias, R. T., Franchini, E., Gualano, B., Kashiwagura, D. B., Solis, M. Y., et al. (2010). Rapid weight loss followed by recovery time does not affect judo-related performance. J. Sports Sci. 28, 21-32. doi: 10.1080/ 02640410903428574

Aziz, A., Chia, M., and Teh, K. (2000). The relationship between maximal oxygen uptake and repeated sprint performance indices in field hockey and soccer players. J. Sports Med. Phys. Fitness 40, 195-200.

Aziz, A. R., Mukherjee, S., Chia, M., and Teh, K. C. (2007). Relationship between measured maximal oxygen uptake and aerobic endurance performance with running repeated sprint ability in young elite soccer players. J. Sports Med. Phys. Fitness 47, 401-407.

Balmer, N. J., Nevill, A. M., and Lane, A. M. (2005). Do judges enhance home advantage in European championship boxing? J. Sports Sci. 23, 409-416. doi: $10.1080 / 02640410400021583$

Balsom, P., Seger, J., Sjödin, B., and Ekblom, B. (1992). Maximal-intensity intermittent exercise: effect of recovery duration. Int. J. Sports Med. 13, 528-528. doi: 10.1055/s-2007-1021311

Barley, O. R., Chapman, D. W., Blazevich, A. J., and Abbiss, C. R. (2018a). Acute dehydration impairs endurance without modulating neuromuscular function. Front. Physiol. 9:1562. doi: 10.3389/fphys.2018.01562

Barley, O. R., Iredale, F., Chapman, D. W., Hopper, A., and Abbiss, C. R. (2018b). Repeat effort performance is reduced 24 hours after acute dehydration in mixed martial arts athletes. J. Strength Cond. Res. 32, 2555-2561. doi: 10.1519/JSC. 0000000000002249

Bassett, D. R. Jr., and Howley, E. T. (2000). Limiting factors for maximum oxygen uptake and determinants of endurance performance. Med. Sci. Sports Exerc. 32, 70-84. doi: 10.1097/00005768-200001000-00012

Bishop, D., Girard, O., and Mendez-Villanueva, A. (2011). Repeated-sprint ability-Part II. Sports Med. 41, 741-756. doi: 10.2165/11590560-00000000000000

Bishop, D., Spencer, M., Duffield, R., and Lawrence, S. (2001). The validity of a repeated sprint ability test. J. Sci. Med. Sport 4, 19-29. doi: 10.1016/S14402440(01)80004-9

Bonato, M., Rampichini, S., Ferrara, M., Benedini, S., Sbriccoli, P., Merati, G., et al. (2015). Aerobic training program for the enhancements of HR and VO2 off-kinetics in elite judo athletes. J. Sports Med. Phys. Fitness 55, 1277-1284.

Bouhlel, E., Jouini, A., Gmada, N., Nefzi, A., Abdallah, K. B., and Tabka, Z. (2006). Heart rate and blood lactate responses during Taekwondo training and competition. Sci. Sports 21, 285-290. doi: 10.1016/j.scispo.2006.08.003

\section{AUTHOR CONTRIBUTIONS}

OB and SG conceptualized the review topic and design. All other authors contributed to the crafting and editing of the manuscript.

Bridge, C. A., da Silva Santos, J. F., Chaabene, H., Pieter, W., and Franchini, E. (2014). Physical and physiological profiles of Taekwondo athletes. Sports Med. 44, 713-733. doi: 10.1007/s40279-014-0159-9

Bruzas, V., Stasiulis, A., Cepulenas, A., Mockus, P., Statkeviciene, B., and Subacius, V. (2014). Aerobic capacity is correlated with the ranking of boxers. Percept. Mot. Skills 119, 50-58. doi: 10.2466/30.29.PMS.119c12z9

Buchheit, M. (2008). The 30-15 intermittent fitness test: accuracy for individualizing interval training of young intermittent sport players. J. Strength Cond. Res. 22, 365-374. doi: 10.1519/JSC.0b013e3181635b2e

Campos, F. A. D., Bertuzzi, R., Dourado, A. C., Santos, V. G. F., and Franchini, E. (2012). Energy demands in Taekwondo athletes during combat simulation. Eur. J. Appl. Physiol. 112, 1221-1228. doi: 10.1007/s00421-011-2071-4

Chaabène, H., Hachana, Y., Franchini, E., Mkaouer, B., Montassar, M., and Chamari, K. (2012). Reliability and construct validity of the karate-specific aerobic test. J. Strength Cond. Res. 26, 3454-3460. doi: 10.1519/JSC. 0b013e31824eddda

Chaabene, H., Negra, Y., Bouguezzi, R., Capranica, L., Franchini, E., Prieske, O., et al. (2018). Tests for the assessment of sport-specific performance in Olympic combat sports: a systematic review with practical recommendations. Front. Physiol. 9:386. doi: 10.3389/fphys.2018.00386

Chaabène, H., Tabben, M., Mkaouer, B., Franchini, E., Negra, Y., Hammami, M., et al. (2015). Amateur boxing: physical and physiological attributes. Sports Med. 45, 337-352. doi: 10.1007/s40279-014-0274-7

Coyle, E. F. (1999). Physiological determinants of endurance exercise performance. J. Sci. Med. Sport 2, 181-189. doi: 10.1016/S1440-2440(99)80172-8

Crisafulli, A., Vitelli, S., Cappai, I., Milia, R., Tocco, F., Melis, F., et al. (2009). Physiological responses and energy cost during a simulation of a Muay Thai boxing match. Appl. Physiol. Nutr. Metab. 34, 143-150. doi: 10.1139/H09-002

Čular, D., Zagatto, A. M., Miliæ, M., Besilja, T., Sellami, M., and Padulo, J. (2018). Validity and reliability of the 30-s continuous jump for anaerobic power and capacity assessment in combat sport. Front. Physiol. 9:543. doi: 10.3389/fphys. 2018.00543

Currell, K., and Jeukendrup, A. E. (2008). Validity, reliability and sensitivity of measures of sporting performance. Sports Med. 38, 297-316. doi: 10.2165/ 00007256-200838040-00003

Del Vecchio, F. B., and Franchini, E. (2013). Specificity of high-intensity intermittent action remains important to MMA athletes physical conditioning: response to Paillard (2011) 1. Percept. Mot. Skills 116, 233-234. doi: 10.2466/25. 05.PMS.116.1.233-234

Del Vecchio, F. B., Hirata, S. M., and Franchini, E. (2011). A review of time-motion analysis and combat development in mixed martial arts matches at regional level tournaments. Percept. Mot. Skills 112, 639-648. doi: 10.2466/05.25.PMS. 112.2.639-648

Doria, C., Veicsteinas, A., Limonta, E., Maggioni, M. A., Aschieri, P., Eusebi, F., et al. (2009). Energetics of karate (kata and kumite techniques) in top-level athletes. Eur. J. Appl. Physiol. 107, 603-610. doi: 10.1007/s00421-009-1154-y

Drust, B., Reilly, T., and Cable, N. (2000). Physiological responses to laboratorybased soccer-specific intermittent and continuous exercise. J. Sports Sci. 18, 885-892. doi: 10.1080/026404100750017814

Durkalec-Michalski, K., Gościań;ska, I., Jeszka, J., and Podgórski, T. (2014). The effect of conventional methods of body weight reduction on overall sense of well-being, body composition and anaerobic capacity of athletes practicing selected combat sports. J. Combat Sport Martial Arts 5, 89-95. doi: 10.5604/ 20815735.1141982

Faude, O., Kindermann, W., and Meyer, T. (2009). Lactate threshold concepts. Sports Med. 39, 469-490. doi: 10.2165/00007256-200939060-00003

Fogelholm, G. M., Koskinen, R., Laakso, J., Rankinen, T., and Ruokonen, I. (1993). Gradual and rapid weight loss: effects on nutrition and performance in male athletes. Med. Sci. Sports Exerc. 25, 371-377. doi: 10.1249/00005768199303000-00012 
Franchini, E., Artioli, G. G., and Brito, C. J. (2013). Judo combat: time-motion analysis and physiology. Int. J. Perform. Anal. Sport 13, 624-641. doi: 10.1080/ 24748668.2013.11868676

Franchini, E., Brito, C. J., and Artioli, G. G. (2012). Weight loss in combat sports: physiological, psychological and performance effects. J. Int. Soc. Sports Nutr. 9:52. doi: 10.1186/1550-2783-9-52

Franchini, E., Brito, C. J., Fukuda, D. H., and Artioli, G. G. (2014). The physiology of judo-specific training modalities. J. Strength Cond. Res. 28, 1474-1481. doi: 10.1519/JSC.0000000000000281

Franchini, E., Nunes, A. V., Moraes, J. M., and Del Vecchio, F. B. (2007). Physical fitness and anthropometrical profile of the Brazilian male judo team. J. Physiol. Anthropol. 26, 59-67. doi: 10.2114/jpa2.26.59

Franchini, E., Sterkowicz, S., Szmatlan-Gabrys, U., Gabrys, T., and Garnys, M. (2011). Energy system contributions to the special judo fitness test. Int. J. Sports Physiol. Perform. 6, 334-343. doi: 10.1123/ijspp.6.3.334

Franchini, E., Takito, M., Kiss, M., and Strerkowicz, S. (2005). Physical fitness and anthropometrical differences between elite and non-elite judo players. Biol. Sport 22:315.

Franchini, E., Vecchio, F. B. D., and Sterkowicz, S. (2009). A special judo fitness test classificatory table. Arch. Budo 5, 127-129.

Garthe, I., Raastad, T., and Sundgot-Borgen, J. (2011). Long-term effect of weight loss on body composition and performance in elite athletes. Int. J. Sport Nutr. Exerc. Metab. 21, 426-435. doi: 10.1123/ijsnem.21.5.426

Girard, O., Mendez-Villanueva, A., and Bishop, D. (2011). Repeated-sprint ability-Part I. Sports Med. 41, 673-694. doi: 10.2165/11590550-00000000000000

Guidetti, L., Musulin, A., and Baldari, C. (2002). Physiological factors in middleweight boxing performance. J. Sports Med. Phys. Fitness 42, 309-314.

Hall, C., and Lane, A. M. (2001). Effects of rapid weight loss on mood and performance among amateur boxers. Br. J. Sports Med. 35, 390-395. doi: 10. 1136/bjsm.35.6.390

Hanon, C., Savarino, J., and Thomas, C. (2015). Blood lactate and acidbase balance of world-class amateur boxers after three 3-minute rounds in international competition. J. Strength Cond. Res. 29, 942-946. doi: 10.1519/JSC. 0000000000000736

Hausen, M., Soares, P. P., Araújo, M. P., Porto, F., Franchini, E., Bridge, C. A., et al. (2017). Physiological responses and external validity of a new setting for taekwondo combat simulation. PLoS One 12:e0171553. doi: 10.1371/journal. pone. 0171553

House, P. D., and Cowan, J. L. (2015). Predicting straight punch force of impact. J. Oklahoma Ass. Health Phys. Educ. Recreat. Dance 53, 1-5. Available at: http://ojs.library.okstate.edu/osu/index.php/OAHPERD/article/view/6296

Iermakov, S., Podrigalo, L. V., and Jagiełło, W. (2016). Hand-grip strength as an indicator for predicting the success in martial arts athletes. Arch. Budo 12, 179-186.

James, L. P., Beckman, E. M., Kelly, V. G., and Haff, G. G. (2016a). The neuromuscular qualities of higher and lower-level mixed martial arts competitors. Int. J. Sports Physiol. Perform. 12, 612-620. doi: 10.1123/ijspp. 2016-0373

James, L. P., Haff, G. G., Kelly, V. G., and Beckman, E. M. (2016b). Towards a determination of the physiological characteristics distinguishing successful mixed martial arts athletes: a systematic review of combat sport literature. Sports Med. 46, 1525-1551. doi: 10.1007/s40279-016-0493-1

James, L. P., Haff, G. G., Kelly, V. G., and Beckman, E. M. (2018). Physiological determinants of mixed martial arts performance and method of competition outcome. Int. J. Sports. Sci. Coach. 13, 978-984. doi: 10.1177/17479541187 80303

Koralsztein, S. D. J., and Billat, V. (2000). Time limit and time at VO2MAX' during a continuous and intermittent run. J. Sports Med. Phys. Fitness 40, 96-102.

Kraemer, W. J., Fry, A. C., Rubin, M. R., Triplett-McBride, T., Gordon, S. E., Koziris, L. P., et al. (2001). Physiological and performance responses to tournament wrestling. Med. Sci. Sports Exerc. 33, 1367-1378. doi: 10.1097/ 00005768-200108000-00019

La Bounty, P., Campbell, B. I., Galvan, E., Cooke, M., and Antonio, J. (2011). Strength and conditioning considerations for mixed martial arts. Strength Cond. J. 33, 56-67. doi: 10.1519/SSC.0b013e3182044304

Lenetsky, S., and Harris, N. (2012). The mixed martial arts athlete: a physiological profile. Strength Cond. J. 34, 32-47. doi: 10.1007/s40279-016-0493-1
Loturco, I., Artioli, G. G., Kobal, R., Gil, S., and Franchini, E. (2014). Predicting punching acceleration from selected strength and power variables in elite karate athletes: a multiple regression analysis. J. Strength Cond. Res. 28, 1826-1832. doi: 10.1519/JSC.0000000000000329

McGawley, K., and Bishop, D. J. (2015). Oxygen uptake during repeated-sprint exercise. J. Sci. Med. Sport 18, 214-218. doi: 10.1016/j.jsams.2014.02.002

Mendes, S. H., Tritto, A. C., Guilherme, J. P. L., Solis, M. Y., Vieira, D. E., Franchini, E., et al. (2013). Effect of rapid weight loss on performance in combat sport male athletes: does adaptation to chronic weight cycling play a role? $\mathrm{Br}$. J. Sports Med. 47, 1155-1160. doi: 10.1136/bjsports-2013-092689

Miarka, B., Coswig, V. S., Vecchio, F. B., Brito, C. J., and Amtmann, J. (2015a). Comparisons of time-motion analysis of mixed martial arts rounds by weight divisions. Int. J. Perform. Anal. Sport 15, 1189-1201. doi: 10.1080/24748668. 2015.11868861

Miarka, B., Vecchio, F., Camey, S., and Amtmann, J. (2015b). Comparisons technical-tactical and time-motion analysis of mixed martial arts by outcomes. J. Strength Cond. Res. 30, 1975-1984. doi: 10.1519/JSC.000000000000 1287

Moore, B., King, D., Kesl, L., Feltmeyer, T., Baldus, P., Sharp, R., et al. (1992). Effect of rapid dehydration and rehydration on work capacity and muscle metabolism during intense exercise in wrestlers. Med. Sci. Sports Exerc. 24:S95. doi: 10.1249/00005768-199205001-00569

Morin, J.-B., Jeannin, T., Chevallier, B., and Belli, A. (2006). Spring-mass model characteristics during sprint running: correlation with performance and fatigue-induced changes. Int. J. Sports Med. 27, 158-165. doi: 10.1055/s-2005837569

Müller, E., Benko, U., Raschner, C., and Schwameder, H. (2000). Specific fitness training and testing in competitive sports. Med. Sci. Sports Exerc. 32, 216-220. doi: 10.1097/00005768-200001000-00032

Oopik, V., Paasuke, M., Timpmann, S., and Medijainen, L. (2002). Effects of creatine supplementation during recovery from rapid body mass reduction on metabolism and muscle performance capacity in well-trained wrestlers. J. Sports Med. Phys. Fitness 42, 330-339.

Ouergui, I., Hammouda, O., Chtourou, H., Gmada, N., and Franchini, E. (2014). Effects of recovery type after a kickboxing match on blood lactate and performance in anaerobic tests. Asian J. Sports Med. 5, 99-107.

Ratamess, N. A. (2011). Strength and conditioning for grappling sports. Strength Cond. J. 33, 18-24. doi: 10.1519/SSC.0b013e31823732c5

Ravier, G., Dugue, B., Grappe, F., and Rouillon, J.-D. (2006). Maximal accumulated oxygen deficit and blood responses of ammonia, lactate and $\mathrm{pH}$ after anaerobic test: a comparison between international and national elite karate athletes. Int. J. Sports Med. 27, 810-817. doi: 10.1055/s-2005-872965

Reale, R., Slater, G., and Burke, L. (2016). Acute weight loss strategies for combat sports and applications to olympic success. Int. J. Sports Physiol. Perform. 12, 142-151. doi: 10.1123/ijspp.2016-0211

Reljic, D., Feist, J., Jost, J., Kieser, M., and Friedmann-Bette, B. (2015). Rapid body mass loss affects erythropoiesis and hemolysis but does not impair aerobic performance in combat athletes. Scand. J. Med. Sci. Sports 26, 507-517. doi: 10.1111/sms.12485

Rodrigues Silva, J. J., Boscolo Del Vecchio, F., Merseburger Picanço, L., Yuri Takito, M., and Franchini, E. (2011). Time-motion analysis in Muay-Thai and kick-boxing amateur matches. J. Hum. Sport Exerc. 6, 490-496. doi: 10.4100/ jhse.2011.63.02

Salci, Y. (2015). The metabolic demands and ability to sustain work outputs during kickboxing competitions. Int. J. Perform. Anal. Sport 15, 39-52. doi: 10.1080/ 24748668.2015.11868775

Sant'Ana, J., Diefenthaeler, F., Dal Pupo, J., Detanico, D., Guglielmo, L. G. A., and Santos, S. G. (2014). Anaerobic evaluation of Taekwondo athletes. Int. SportMed J. 15, 492-499.

Sant'Ana, J., Franchini, E., da Silva, V., and Diefenthaeler, F. (2017). Effect of fatigue on reaction time, response time, performance time, and kick impact in taekwondo roundhouse kick. Sports Biomech. 16, 201-209. doi: 10.1080/ 14763141.2016.1217347

Smith, M. (1998). Sport Specific Ergometry and the Physiological Demands of Amateur Boxing. Ph.D. thesis, Chichester University, Chichester.

Smith, M., Dyson, R., Hale, T., Harrison, J., and McManus, P. (2000). The effects in humans of rapid loss of body mass on a boxing-related task. Eur. J. Appl. Physiol. 83, 34-39. doi: 10.1007/s004210000251 
Spencer, M., Bishop, D., Dawson, B., and Goodman, C. (2005). Physiological and metabolic responses of repeated-sprint activities. Sports Med. 35, 1025-1044. doi: 10.2165/00007256-200535120-00003

Tack, C. (2013). Evidence-based guidelines for strength and conditioning in mixed martial arts. Strength Cond. J. 35, 79-92. doi: 10.1519/SSC.0b013e3182a62fef

Timpmann, S., Ööpik, V., Pääsuke, M., Medijainen, L., and Ereline, J. (2008). Acute effects of self-selected regimen of rapid body mass loss in combat sports athletes. J. Sports Sci. Med. 7, 210-217.

Tomlin, D. L., and Wenger, H. A. (2001). The relationship between aerobic fitness and recovery from high intensity intermittent exercise. Sports Med. 31, 1-11. doi: 10.2165/00007256-200131010-00001

Vandewalle, H., Péerès, G., and Monod, H. (1987). Standard anaerobic exercise tests. Sports Med. 4, 268-289. doi: 10.2165/00007256-198704040-00004

Villar, R., Gillis, J., Santana, G., Pinheiro, D. S., and Almeida, A. (2016). Association between anaerobic metabolic demands during simulated Brazilian jiu-jitsu combat and specific jiu-jitsu anaerobic performance test: Brazilian jiu-jitsu combat and anaerobic performance test. J. Strength Cond. Res. 32, 432-440. doi: 10.1519/JSC.0000000000001536
Yang, W.-H., Heine, O., and Grau, M. (2018). Rapid weight reduction does not impair athletic performance of Taekwondo athletes-a pilot study. PLoS One 13:e0196568. doi: 10.1371/journal.pone.0196568

Zagatto, A. M., Beck, W. R., and Gobatto, C. A. (2009). Validity of the running anaerobic sprint test for assessing anaerobic power and predicting shortdistance performances. J. Strength Cond. Res. 23, 1820-1827. doi: 10.1519/JSC. 0b013e3181b3df32

Conflict of Interest Statement: The authors declare that the research was conducted in the absence of any commercial or financial relationships that could be construed as a potential conflict of interest.

Copyright (C) 2019 Barley, Chapman, Guppy and Abbiss. This is an open-access article distributed under the terms of the Creative Commons Attribution License (CC BY). The use, distribution or reproduction in other forums is permitted, provided the original author(s) and the copyright owner(s) are credited and that the original publication in this journal is cited, in accordance with accepted academic practice. No use, distribution or reproduction is permitted which does not comply with these terms. 